\title{
FAKTOR-FAKTOR YANG BERHUBUNGAN DENGAN MOTIVASI PERAWAT UNTUK TERLIBAT DALAM AKREDITASI DI RSUD KUDUNGGA
}

\author{
Merlinda Sampe ${ }^{1}$, Suwanto ${ }^{2}$, Abdurrahman ${ }^{3}$ \\ ${ }^{1}$ Prodi Ilmu Keperawatan, ITKES Wiyata Husada, Jl. Kadrie Oening No. 77, \\ Samarinda, Kalimantan Timur. \\ e-mail : merlindas78@gmail.com \\ ${ }^{2}$ Prodi Ilmu Keperawatan, ITKES Wiyata Husada, J1. Kadrie Oening No. 77, \\ Samarinda, Kalimantan Timur. e-mail :wanto_71ymail.com \\ ${ }^{3}$ Prodi Ilmu Keperawatan, ITKES Wiyata Husada, Jl. Kadrie Oening No. 77, \\ Samarinda, Kalimantan Timur. e-mail :abdurrahman150785@gmail.com
}

\begin{abstract}
Abstrak
Latar Belakang : Akreditasi merupakan pengakuan yang diberikan kepada Rumah Sakit karena telah berupaya meningkatkan mutu pelayanan secara berkesinambungan. Data akreditasi tahap II di RSUD Kudungga diperoleh kinerja perawat dalam kesiapan akreditasi hanya mencapai $40 \%$, hal ini dapat dikarenakan perawat dalam menghadapi akreditasi Rumah Sakit kurang memiliki motivasi. Tujuan : Untuk mengetahui faktor-faktor yang berhubungan dengan motivasi perawat untuk terlibat dalam akreditasi di RSUD Kudungga. Metode : Jenis penelitian yang dilakukan adalah kuantitatif dengan rancangan survei analitik dan desain cross sectional. Populasi dari penelitian ini adalah semua perawat PNS di RSUD Kudungga sebanyak 62 orang, berdasarkan rumus slovin diperoleh sampel sebanyak 51 orang. Analisis data menggunakan chi square. Hasil Penelitian : Hasil analisis didapatkan bahwa terdapat hubungan antara pengakuan atas prestasi, pengembangan potensial individu, kebijakan institusi dan pengawasan dengan motivasi perawat untuk terlibat dalam akreditasi dengan nilai $p<$ alpha 0,05 . Kesimpulan : pengakuan atas prestasi, pengembangan potensial individu, kebijakan institusi dan pengawasan merupakan faktor yang berhubungan dengan motivasi. Disarankan Pihak RSUD Kudungga hendaknya megupayakan penerapan dan pengawasan kebijakan terkait dengan motivasi perawat untuk terlibat dalam akreditasi di RSUD Kudungga.
\end{abstract}

Kata Kunci : Motivasi, Perawat, Akreditasi, Rumah Sakit.

\section{PENDAHULUAN}

Salah satu upaya pemerintah untuk mendorong agar Rumah Sakit mengutamakan pelayanan, keselamatan dan perlindungan kepada masyarakat adalah dengan mewajibkan Rumah Sakit untuk melakukan akreditasi. Menurut Joint Commission International (JCI) mengevaluasi pada tahun 2017 lebih dari 21.000 Rumah Sakit atau lembaga dan program pelayanan kesehatan di dunia yang mendapatkan standar akreditasi (Smarter Health, 2018). Berdasarkan data JCI tahun 2019 jumlah Rumah Sakit di dunia yang 
terakreditasi yaitu 19.880 dari 100 negara (JCI, 2019).

Data Badan Penyelenggara Jaminan

Sosial Kesehatan menyebutkan, hingga

Desember 2018 dari total 2.217 Rumah Sakit

yang bekerja sama dengan

Badan

Penyelenggara Jaminan Sosial Kesehatan, sebanyak 1.759 yang sudah terakreditasi. Artinya masih ada 458 Rumah Sakit provider BPJS Kesehatan yang belum terakreditasi hingga akhir 2018 (Badan Penyelenggara Jaminan Sosial Kesehatan, 2019). Di Sulawesi Selatan secara umum dari 75 Rumah Sakit yang ada, hingga tahun 2012 baru sekitar 52 (68\%) Rumah Sakit yang telah terakreditasi versi akreditasi lama (Talakua, 2013). Untuk jumlah Rumah Sakit yang sudah terakreditasi di Pulau Jawa pada tahun 2019 meliputi Jawa Timur sebanyak 326 Rumah Sakit dari total 380 Rumah Sakit (Almutoif, 2019), Jawa Barat sebanyak 94 Rumah Sakit dari total 328 Rumah Sakit (Humas Pemprov Jabar, 2019). Adapun Rumah Sakit di Pulau Kalimantan yang sudah akreditasi tahun 2019 sebanyak 93 Rumah Sakit dari total 168 Rumah Sakit. Rumah Sakit yang sudah akreditasi di Kalimantan Timur pada tahun 2019 yaitu ada 28 Rumah Sakit dan 16 Rumah Sakit yang belum memiliki akreditasi (Bontang Post, 2019).
Di Kabupaten Kutai Timur yang terletak di Provinsi Kalimantan Timur menurut Komisi KARS (Komisi Akreditasi Rumah Sakit, 2017) terdapat lima Rumah Sakit umum dan swasta telah terakreditasi nasional. Kelima Rumah Sakit itu adalah

RSUD Kudungga Sangatta, RSUD Sangkulirang, RS Umum Medika Sanggatta, RS Pupuk Kaltim Prima Sangatta dan RS Umum Meloy (Kaltim News, 2019).

Untuk meningkatkan akreditasi perlu adanya motivasi perawat terlibat dalam akreditasi. Motivasi kerja adalah proses yang bersifat internal atau eksternal bagi setiap pegawai yang menyebabkan timbulnya sikap antusias dan persistensi dalam melaksanakan tugas. Motivasi dapat juga diartikan bahwa teknik motivasi harus dapat memastikan bahwa lingkungan dimana mereka bekerja dapat memenuhi sejumlah kebutuhannya (Wibowo, 2017).

Menurut hasil penelitian Cahyani (2016) menunjukkan bahwa variabel yang berhubungan dengan motivasi kerja meliputi umur, masa kerja, prestasi kerja, pengakuan, pengembangan potensial individu, persepsi gaji, kondisi kerja, kebijakan dan administrasi, hubungan antar pribadi, dan supervisi. Sedangkan variabel yang tidak berhubungan 
yaitu status perkawinan, pekerjaan itu sendiri, dan tanggung jawab.

Menurut data akreditasi tahap II di RSUD Kudungga pada tanggal 24 Juni 2019 sudah dilakukan Survei Akreditasi Standar Nasional Akreditasi Rumah Sakit (SNARS) edisi 1 terhadap RSUD Kudungga Sangatta. Penurunan kinerja perawat dalam kesiapan akreditasi ini dapat dilihat dari hasil SNARS edisi 1 yang hanya mencapai 40\%. Dijelaskan bahwa masih banyak aspek penilaian yang perlu dilengkapi agar memenuhi standar. Hasil Self Assessment (Kajian Mandiri) RSUD Kudungga telah cukup baik yaitu sekitar 70\%. Hasil self assessment yang dilakukan Rumah Sakit bertolak belakang dengan hasil SNARS edisi 1.

Berdasarkan hasil studi pendahuluan pada tanggal 16 Maret 2020 di RSUD Kudungga, dilakukan wawancara tentang motivasi perawat dalam menghadapi akreditasi Rumah Sakit pada perawat dengan jumlah 15 orang, terdapat 11 orang mengatakan dari mereka kurang termotivasi untuk terlibat dalam akreditasi dikarenakan kurang adanya penghargaan terhadap perawat yang berprestasi, kurangnya pengadaan pelatihan untuk mengembangkan kemampuan perawat dalam memberikan pelayanan, gaji yang diterima sudah sesuai harapan namun terkadang tidak mencukupi dan kurangnya pengawasan oleh pimpinan. Selain itu, 4 orang diantaranya mengatakan sangat bermotivasi dalam keterlibatan akreditasi dikarenakan gaji yang diterima sudah sesuai dan mendapatkan pelatihan dalam mengembangkan potensi.

\section{METODE}

Jenis penelitian yang dilakukan adalah penelitian kuantitatif dengan rancangan penelitian survei analitik dan desain cross sectional. Populasi dari penelitian ini adalah semua perawat PNS di RSUD Kudungga sebanyak 62 orang. Menurut perhitungan rumus slovin diperoleh sampel yaitu perawat PNS di RSUD Kudungga sebanyak 51 orang. Dalam penelitian ini sampel diambil berdasarkan ruang rawat inap dan rawat jalan di RSUD Kudungga dengan teknik sampling yang digunakan adalah random sampling dengan metode proporsional random sampling. Analisa data pada penelitian ini menggunakan Chi Square. 


\section{HASIL}

\begin{tabular}{|c|c|c|c|c|c|c|c|c|}
\hline \multirow{3}{*}{ No } & \multirow{3}{*}{$\begin{array}{c}\text { Pengakuan } \\
\text { Atas } \\
\text { Prestasi }\end{array}$} & \multicolumn{4}{|c|}{$\begin{array}{c}\text { Motivasi Untuk } \\
\text { Terlibat Dalam } \\
\text { Akreditasi }\end{array}$} & \multirow{3}{*}{ Total } & \multirow{3}{*}{$\%$} & \multirow{3}{*}{$\begin{array}{c}p \\
\text { value }\end{array}$} \\
\hline & & \multicolumn{2}{|c|}{ Baik } & \multicolumn{2}{|c|}{$\begin{array}{c}\text { Kurang } \\
\text { Baik }\end{array}$} & & & \\
\hline & & $\mathrm{n}$ & $\%$ & $\mathrm{n}$ & $\%$ & & & \\
\hline & & 16 & 31,4 & 9 & 17,6 & & & \\
\hline 2 & $\begin{array}{l}\text { Kurang } \\
\text { Baik }\end{array}$ & 8 & 15,7 & 18 & 35,3 & 26 & 51 & $* 0,036$ \\
\hline
\end{tabular}

Tabel 1. Hubungan pengakuan atas prestasi dengan motivasi perawat untuk terlibat dalam akreditasi

\begin{tabular}{llllllll}
1 & Baik & & & & & 25 & 49 \\
& & & & & & & \\
\hline \multirow{2}{*}{ Jumlah } & 24 & 47,1 & 27 & 52,9 & 51 & 100 \\
\hline
\end{tabular}

Tabel 2. Hubungan pengembangan potensial individu dengan motivasi perawat untuk terlibat dalam akreditasi

\begin{tabular}{|c|c|c|c|c|c|c|c|c|}
\hline \multirow{3}{*}{ No } & \multirow{3}{*}{$\begin{array}{c}\text { Pengembangan } \\
\text { Potensial } \\
\text { Individu }\end{array}$} & \multicolumn{4}{|c|}{$\begin{array}{c}\text { Motivasi Untuk Terlibat } \\
\text { Dalam Akreditasi }\end{array}$} & \multirow{3}{*}{ Total } & \multirow{3}{*}{$\%$} & \multirow{3}{*}{$\begin{array}{c}p \\
\text { value }\end{array}$} \\
\hline & & \multicolumn{2}{|c|}{ Baik } & \multicolumn{2}{|c|}{$\begin{array}{c}\text { Kurang } \\
\text { Baik } \\
\end{array}$} & & & \\
\hline & & & & $\mathrm{n}$ & & & & \\
\hline 1 & Baik & 18 & 35,3 & 9 & 17,6 & 27 & 52,9 & \\
\hline \multirow[t]{2}{*}{2} & Kurang Baik & 6 & 11,8 & 18 & 35,3 & 24 & 47,1 & $* 0,007$ \\
\hline & Jumlah & 24 & 47,1 & 27 & 52,9 & 51 & 100 & \\
\hline
\end{tabular}

Tabel 3. Hubungan kebijakan institusi dengan motivasi perawat untuk terlibat dalam akreditasi

\begin{tabular}{|c|c|c|c|c|c|c|c|c|}
\hline \multirow{3}{*}{ No } & \multirow{3}{*}{ Pengawasan } & \multicolumn{4}{|c|}{$\begin{array}{c}\text { Motivasi Untuk Terlibat } \\
\text { Dalam Akreditasi } \\
\end{array}$} & \multirow{3}{*}{ Total } & \multirow{3}{*}{$\%$} & \multirow{3}{*}{$\begin{array}{c}p \\
\text { value }\end{array}$} \\
\hline & & \multicolumn{2}{|c|}{ Baik } & \multicolumn{2}{|c|}{$\begin{array}{c}\begin{array}{c}\text { Kurang } \\
\text { Baik }\end{array} \\
\end{array}$} & & & \\
\hline & & $\mathrm{n}$ & $\%$ & $\mathrm{n}$ & $\%$ & & & \\
\hline 1 & Baik & 18 & 35,3 & 7 & 13,7 & 25 & 49 & \multirow{3}{*}{$* 0,001$} \\
\hline \multirow[t]{2}{*}{2} & $\begin{array}{l}\text { Kurang } \\
\text { Baik } \\
\end{array}$ & 6 & 11,8 & 20 & 39,2 & 26 & 51 & \\
\hline & Jumlah & 24 & 47,1 & 27 & 52,9 & 51 & 100 & \\
\hline \multirow{3}{*}{ No } & \multirow{3}{*}{$\begin{array}{l}\text { Kebijakan } \\
\text { Institusi }\end{array}$} & \multicolumn{4}{|c|}{$\begin{array}{c}\text { Motivasi Untuk Terlibat } \\
\text { Dalam Akreditasi }\end{array}$} & \multirow{3}{*}{ Total } & \multirow{3}{*}{$\%$} & \multirow{3}{*}{$\begin{array}{c}p \\
\text { value }\end{array}$} \\
\hline & & \multicolumn{2}{|c|}{ Baik } & \multicolumn{2}{|c|}{$\begin{array}{c}\text { Kurang } \\
\text { Baik }\end{array}$} & & & \\
\hline & & & & \multicolumn{2}{|l|}{$\mathrm{n}$} & & & \\
\hline 1 & Baik & 15 & 29,4 & 7 & 13,7 & 22 & 43,1 & \\
\hline 2 & $\begin{array}{l}\text { Kurang } \\
\text { Baik }\end{array}$ & 9 & 17,6 & 20 & 39,2 & 29 & 56,9 & $* 0,019$ \\
\hline 1 & & & $\%$ & & & & & $\%$ \\
\hline & Jumlah & 24 & 47,1 & 27 & 52,9 & 51 & 100 & \\
\hline
\end{tabular}

Tabel 4. Hubungan pengawasan dengan motivasi perawat untuk terlibat dalam akreditasi di RSUD Kudungga

Pembahasan Hubungan pengakuan atas prestasi dengan motivasi perawat untuk terlibat dalam akreditasi

Berdasarkan hasil penelitian mengenai hubungan pengakuan atas prestasi dengan motivasi perawat untuk terlibat dalam akreditasi di RSUD Kudungga, diperoleh 25 
responden yang menyatakan pengakuan atas prestasi baik, maka proporsi tertinggi pada motivasi untuk terlibat dalam akreditasi baik berjumlah 16 responden $(31,4 \%)$, namun terdapat yang menyatakan pengakuan atas prestasi baik akan tetapi motivasi untuk terlibat dalam akreditasi kurang baik berjumlah 9 responden (17,6\%). Hal ini dikarenakan walaupun perawat selalu mendapatkan pujian dari atasan, terdorong untuk ikut memberi pendapat dalam pengambilan keputusan, pendapat di dengar atasan, status hukum kepegawaian terjamin dan punya kesempatan mengusulkan sesuatu untuk kemajuan rumah sakit, namun perawat merasa prestasi kerja bukan hal utama yang mendorong secara efektif dalam meningkatkan akreditasi di rumah sakit, sering menghindari jika diminta mewakilkan kepala ruangan dalam menetapkan kebijakan akreditasi di rumah sakit dan kurang bekerja sama dengan perawat lainnya dalam melakukan akreditasi di rumah sakit.

Terdapat juga 26 responden yang menyatakan pengakuan atas prestasi kurang baik, maka proporsi tertinggi pada motivasi untuk terlibat dalam akreditasi kurang baik berjumlah 18 responden (35,3\%), namun terdapat responden yang menyatakan pengakuan atas prestasi kurang baik akan tetapi motivasi untuk terlibat dalam akreditasi baik berjumlah 8 responden $(15,7 \%)$. Hal ini dikarenakan walaupun perawat jarang mendapatkan pujian dari atasan, kurang terdorong untuk ikut memberi pendapat dalam pengambilan keputusan, pendapat kurang di dengar atasan, dan jarang punya kesempatan mengusulkan sesuatu untuk kemajuan rumah sakit, namun perawat berusaha agar pelaksanaan akreditasi di rumah sakit berhasil dengan baik, bekerja sama dengan perawat lainnya dalam melakukan akreditasi di rumah sakit, merasa puas dengan akreditasi di rumah sakit capai selama ini dan dalam berkerja saya ingin maju dan berkembang.

Hasil uji statistik diperoleh hasil $p$ value : 0,036< $\alpha: 0,05$ sehingga Ho ditolak dan Ha diterima yaitu ada hubungan pengakuan atas prestasi dengan motivasi perawat untuk terlibat dalam akreditasi di RSUD Kudungga. Hasil penelitian ini sesuai dengan penelitian Cahyani (2016) ada hubungan pengakuan atas prestasi kerja dengan motivasi kerja pada perawat rumah sakit jiwa Bangsal Kelas III RSJD Dr. Amino Gondohutomo Provinsi Jawa Tengah. Begitupula penelitian Iqrar (2016) yang menunjukkan bahwa ada hubungan pengakuan atas prestasi kerja dengan motivasi kerja Pegawai Non Medis di Rumah Sakit Umum Hasanah Graha Afiah Di Depok Jawa Barat. Adapun hasil penelitian Damayanti (2014) 
menunjukkan bahwa ada hubungan prestasi terhadap motivasi kerja pegawai tetap di Rumah Sakit Umum Daerah Kabupaten Penajam Paser Utara.

Menurut asumsi peneliti, ada hubungan pengakuan atas prestasi dengan motivasi perawat untuk terlibat dalam akreditasi di RSUD Kudungga. Dimana pengakuan atas pencapaian prestasi dalam diri perawat di rumah sakit belum maksimal, sehingga kurangnya motivasi perawat terlibat akreditasi.

\section{Hubungan pengembangan potensial individu dengan motivasi perawat untuk terlibat dalam akreditasi}

Berdasarkan hasil penelitian mengenai hubungan pengembangan potensial individu dengan motivasi perawat untuk terlibat dalam akreditasi di RSUD Kudungga, diperoleh 27 responden yang menyatakan pengembangan potensial individu baik, maka proporsi tertinggi pada motivasi untuk terlibat dalam akreditasi baik berjumlah 18 responden $(35,3 \%)$, namun terdapat responden yang menyatakan pengembangan potensial individu baik akan tetapi motivasi untuk terlibat dalam akreditasi kurang baik berjumlah 9 responden $(17,6 \%)$. Hal ini dikarenakan perawat mendapatkan kesempatan untuk pelatihan tingkat lanjut pada bidang pekerjaan, mendapatkan kesempatan untuk belajar hal-hal baru dan mendapatkan kesempatan untuk promosi karir. Namun perawat merasa prestasi kerja bukan hal utama yang mendorong secara efektif dalam meningkatkan akreditasi di rumah sakit, sering menghindari jika diminta mewakilkan kepala ruangan dalam menetapkan kebijakan akreditasi di rumah sakit dan kurang bekerja sama dengan perawat lainnya dalam melakukan akreditasi di rumah sakit.

Terdapat pula 24 responden yang menyatakan pengembangan potensial individu kurang baik, maka proporsi tertinggi pada motivasi untuk terlibat dalam akreditasi kurang baik berjumlah 18 responden $(35,3 \%)$, namun terdapat responden yang menyatakan pengembangan potensial individu kurang baik akan tetapi motivasi untuk terlibat dalam akreditasi baik berjumlah 6 responden $(11,8 \%)$. Hal ini dikarenakan walaupun perawat kurang mendapatkan kesempatan untuk pelatihan tingkat lanjut pada bidang pekerjaan, kurang mendapatkan kesempatan untuk belajar hal-hal baru dan kurang mendapatkan kesempatan untuk promosi karir. Namun perawat berusaha agar pelaksanaan akreditasi di rumah sakit berhasil dengan baik, bekerja sama dengan perawat lainnya dalam melakukan akreditasi di rumah sakit, merasa puas dengan akreditasi di rumah sakit capai selama ini dan dalam berkerja saya ingin maju dan berkembang. 
Hasil uji statistik diperoleh hasil $p$ value : 0,007< $<$ : 0,05 sehingga Ho ditolak dan $\mathrm{Ha}$ diterima yaitu ada hubungan pengembangan potensial individu dengan motivasi perawat untuk terlibat dalam akreditasi di RSUD Kudungga. Hasil penelitian ini sesuai dengan penelitian Cahyani (2016) ada hubungan pengembangan potensial individu dengan motivasi kerja pada perawat rumah sakit jiwa Bangsal Kelas III RSJD Dr. Amino Gondohutomo Provinsi Jawa Tengah. Begitupula penelitian Iqrar (2016) yang menunjukkan bahwa ada hubungan pengembangan potensial individu dengan motivasi kerja Pegawai Non Medis di Rumah Sakit Umum Hasanah Graha Afiah Di Depok Jawa Barat. Adapun hasil penelitian Damayanti (2014) menunjukkan bahwa ada hubungan kesempatan untuk maju dengan motivasi kerja pegawai tetap di Rumah Sakit Umum Daerah Kabupaten Penajam Paser

Utara.

Menurut asumsi peneliti, ada hubungan pengembangan potensial individu dengan motivasi perawat untuk terlibat dalam akreditasi di RSUD Kudungga. Dimana kurangnya kesempatan pegawai dalam pengembangan potensial individu menyebabkan kurangnya motivasi perawat untuk terlibat dalam akreditasi.

\section{Hubungan kebijakan institusi dengan motivasi perawat untuk terlibat dalam akreditasi}

Berdasarkan hasil penelitian mengenai hubungan kebijakan institusi dengan motivasi perawat untuk terlibat dalam akreditasi di RSUD Kudungga, diperoleh 22 responden yang menyatakan kebijakan institusi baik, maka proporsi tertinggi pada motivasi untuk terlibat dalam akreditasi baik berjumlah 15 responden $(29,4 \%)$, namun terdapat yang kurang baik berjumlah 7 responden $(13,7 \%)$. Hal ini dikarenakan peraturan, SOP dan instruksi kerja di RS disosialisasikan secara terbuka dan diperbolehkan memberikan masukan dalam menyusun kebijakan rumah sakit. Namun perawat merasa prestasi kerja bukan hal utama yang mendorong secara efektif dalam meningkatkan akreditasi di rumah sakit, sering menghindari jika diminta mewakilkan kepala ruangan dalam menetapkan kebijakan akreditasi di rumah sakit dan kurang bekerja sama dengan perawat lainnya dalam melakukan akreditasi di rumah sakit.

Terdapat pula 29 responden yang menyatakan kebijakan institusi kurang baik, maka proporsi tertinggi pada motivasi untuk terlibat dalam akreditasi kurang baik berjumlah 20 responden $(39,2 \%)$, namun terdapat yang 
baik berjumlah 9 responden $(17,6 \%)$. Hal ini dikarenakan perawat tidak mengetahui ada kebijakan peraturan, SOP dan instruksi kerja di RS kurang disosialisasikan secara terbuka dan perawat tidak diperbolehkan memberikan masukan dalam menyusun kebijakan rumah sakit. Namun perawat berusaha agar pelaksanaan akreditasi di rumah sakit berhasil dengan baik, bekerja sama dengan perawat lainnya dalam melakukan akreditasi di rumah sakit, merasa puas dengan akreditasi di rumah sakit capai selama ini dan dalam berkerja saya ingin maju dan berkembang.

Hasil uji statistik diperoleh hasil $p$ value : 0,019< $\alpha: 0,05$ sehingga Ho ditolak dan Ha diterima yaitu ada hubungan kebijakan institusi dengan motivasi perawat untuk terlibat dalam akreditasi di RSUD Kudungga. Hasil penelitian ini sesuai dengan penelitian Cahyani (2016) ada hubungan kebijakan institusi dengan motivasi kerja pada perawat rumah sakit jiwa Bangsal Kelas III RSJD Dr. Amino Gondohutomo Provinsi Jawa Tengah. Begitupula penelitian Iqrar (2016) yang menunjukkan bahwa ada hubungan kebijakan institusi dengan motivasi kerja Pegawai Non Medis di Rumah Sakit Umum Hasanah Graha Afiah Di Depok Jawa Barat. Adapun hasil penelitian Damayanti (2014) menunjukkan bahwa ada hubungan kebijakan institusi dengan motivasi kerja pegawai tetap di Rumah Sakit Umum Daerah Kabupaten Penajam Paser Utara.

Menurut asumsi peneliti, ada hubungan kebijakan institusi dengan motivasi perawat untuk terlibat dalam akreditasi di RSUD Kudungga, dimana masih terdapat beberapa kebijakan di rumah sakit yang tidak di taati membuat masih kurangnya motivasi perawat untuk terlibat dalam akreditasi.

\section{Hubungan pengawasan dengan motivasi perawat untuk terlibat dalam akreditasi}

Berdasarkan hasil penelitian mengenai hubungan pengawasan dengan motivasi perawat untuk terlibat dalam akreditasi di RSUD Kudungga, diperoleh 25 responden yang menyatakan pengawasan baik, maka proporsi tertinggi pada motivasi untuk terlibat dalam akreditasi baik berjumlah 18 responden $(35,3 \%)$, namun terdapat responden yang menyatakan pengawasan baik akan tetapi motivasi untuk terlibat dalam akreditasi kurang baik berjumlah 7 responden $(13,7 \%)$. Hal ini dikarenakan kepala ruangan melakukan pemantauan dengan baik, kepala ruangan memberikan bimbingan, kepala ruangan membantu menyelesaikan masalah yang terkait dengan tugas secara bijaksana dan memberikan teguran lisan apabila melakukan kesalahan. Namun perawat merasa prestasi kerja bukan hal 
utama yang mendorong secara efektif dalam meningkatkan akreditasi di rumah sakit, sering menghindari jika diminta mewakilkan kepala ruangan dalam menetapkan kebijakan akreditasi di rumah sakit dan kurang bekerja sama dengan perawat lainnya dalam melakukan akreditasi di rumah sakit.

Terdapat pula 26 responden yang menyatakan pengawasan kurang baik, maka proporsi tertinggi pada motivasi untuk terlibat dalam akreditasi kurang baik berjumlah 20 responden $(39,2 \%)$, namun terdapat responden yang menyatakan pengawasan kurang baik akan tetapi motivasi untuk terlibat dalam akreditasi kurang baik berjumlah 6 responden $(11,8 \%)$. Hal ini dikarenakan kepala ruangankurang melakukan pemantauan dengan baik, kepala ruangan kurang memberikan bimbingan, kepala ruangan tidak membantu menyelesaikan masalah yang terkait dengan tugas secara bijaksana dan kurang memberikan teguran lisan apabila melakukan kesalahan. Namun perawat berusaha agar pelaksanaan akreditasi di rumah sakit berhasil dengan baik, bekerja sama dengan perawat lainnya dalam melakukan akreditasi di rumah sakit, merasa puas dengan akreditasi di rumah sakit capai selama ini dan dalam berkerja saya ingin maju dan berkembang.
Hasil uji statistik diperoleh hasil $p$ value : 0,001< $\alpha: 0,05$ sehingga Ho ditolak dan Ha diterima yaitu ada hubungan pengawasan dengan motivasi perawat untuk terlibat dalam akreditasi di RSUD Kudungga. Hasil penelitian ini sesuai dengan penelitian Cahyani (2016) ada hubungan pengawasan dengan motivasi kerja pada perawat rumah sakit jiwa Bangsal Kelas III RSJD Dr. Amino Gondohutomo Provinsi Jawa Tengah. Begitupula penelitian Iqrar (2016) yang menunjukkan bahwa ada hubungan pengawasan dengan motivasi kerja Pegawai Non Medis di Rumah Sakit Umum Hasanah Graha Afiah Di Depok Jawa Barat. Adapun hasil penelitian Damayanti (2014) menunjukkan bahwa ada hubungan pengawasan dengan motivasi kerja pegawai tetap di Rumah Sakit Umum Daerah

Kabupaten Penajam Paser Utara.

Menurut asumsi peneliti ada hubungan pengawasan dengan motivasi perawat untuk terlibat dalam akreditasi di RSUD Kudungga. Dimana masih kurangnya pengawasan di RSUD Kudungga, membuat masih kurangnya motivasi perawat untuk terlibat dalam akreditasi.

\section{KESIMPULAN}

1. Ada hubungan pengakuan atas prestasi dengan motivasi perawat untuk terlibat 
dalam akreditasi di RSUD Kudungga ( $p$ value : $0,036<\alpha: 0,05)$.

2. Ada hubungan pengembangan potensial individu dengan motivasi perawat untuk terlibat dalam akreditasi di RSUD Kudungga ( $p$ value : $0,007<\alpha: 0,05)$.

3. Ada hubungan kebijakan institusi dengan motivasi perawat untuk terlibat dalam akreditasi di RSUD Kudungga ( $p$ value : $0,019<\alpha: 0,05)$.

4. Ada hubungan pengawasan dengan motivasi perawat untuk terlibat dalam akreditasi di RSUD Kudungga ( $p$ value : $0,001<\alpha: 0,05)$.

\section{UCAPAN TERIMA KASIH}

Terima kasih Pihak RSUD Kudungga yang telah banyak membantu dalam usaha memperoleh data yang saya perlukan.

\section{REFERENSI}

Badan Penyelenggara Jaminan Sosial Kesehatan. 2019. Info BPJS. https://www.bpjskesehatan.go.id/bpjs/d mdocuments/37 8e285ad1fc54015e8cd9e7c56f1046.p df

\section{Bontang Post. 2019. Puluhan RS Belum}

Terakreditasi.

https://bontangpost.id/57224-

puluhanrs-belum-terakreditasi/
Cahyani, Intan Dwi. 2016. Faktor-faktor yang berhubungan dengan motivasi kerja pada perawat rumah sakit jiwa (Studi Pada Bangsal Kelas III RSJD Dr. Amino Gondohutomo Provinsi Jawa Tengah). Jurnal Kesehatan Masyarakat. Volume 2 Nomor 2.

Damayanti, Sisvana. 2014. Faktor-faktor yang berhubungan dengan motivasi kerja pegawai tetap di RSUD Kabupaten Penajam Paser Utara Kalimantan Timur. Jurnal ARSI.

Iqrar, Ramadhan. 2016. Gambaran Motivasi Kerja Pegawai Non Medis Di Rumah Sakit Umum Hasanah Graha Afiah Di Depok Jawa Barat Tahun 2016. Skripsi Fakultas Kedokteran dan Ilmu Kesehatan. Univeristas Islam Negeri Syarif Hidayatullah Jakarta.

JCI. 2019. Joint Commission International announces publication of 7 th Edition of International Accreditation Standards for Hospitals. https://www.jointcommissioninternati onal.org/en/

Kaltim News. 2019. Lima Rumah Sakit Yang Terakreditasi Di Kaltim. https://kaltim.idntimes.com/news/kalti $\mathrm{m}$ /humas-kutai-timur/lima-rumahsakit.

Talakua, Patricia. 2013. Gambaran motivasi karyawan dalam menghadapi akreditasi di Rumah Sakit Stella Maris Makasar. Jurnal Fakultas Kesehatan Masyarakat, UNHAS, Makassar.

Wibowo. 2017. Manajemen Kinerja. Jakarta: PT. Raja Grafindo Persada. 